\title{
One Year Follow Up after Septal Myectomy for Hypertrophic Obstructive Cardiomyopathy
}

\author{
Ahmed M. El Ashkar ${ }^{1}$, Ahmed N. Khallaf ${ }^{2}$
}

Cardiothoracic Surgery, ${ }^{1}$ Beni-suef University, Beni-suef, ${ }^{2}$ Fayoum University, Fayoum, Egypt

Corresponding author: Ahmed El Ashkar, Phone: 01222149535, E-mail: aelashkar@gmail.com

\begin{abstract}
Background: According to the European society of cardiology 2008, hypertrophic cardiomyopathies (HCM) are defined as increased ventricular wall thickness or mass, in the absence of loading conditions such as hypertension or valve disease.

Objectives: The aim of the current study was to assess the short term (1 year) outcome of the Septal Myectomy for Hypertrophic Obstructive Cardiomyopathy (HOaCM).

Patients and Methods: The study included 31 patients who underwent septal myectomy at Kasr El Einy University Hospital, to assess the short term (1 year) outcome of the procedure. This prospective study was done during the period between March 2014 and May 2018 excluding any patient with ischemic or rheumatic pathology or requiring any additional procedure.

Results: All patients had an LVOT peak gradient of more than $50 \mathrm{mmHg}$. All of the patients had preoperative mitral regurge. The preoperative septal wall thickness ranged from 1.5 to $3.5 \mathrm{~cm}$ with a mean of $2.1 \pm 0.7 \mathrm{~cm}$. TEE showed a pressure gradient across the LVOT ranging from 4 to $20 \mathrm{mmHg}$ with a mean of $7 \pm 6 \mathrm{mmHg}$, which was statistically significant in comparison to the preoperative values. Echocardiography done at one year follow up showed a peak systolic gradient across the LVOT ranging from 6 to $40 \mathrm{mmHg}$, with a mean of $18 \pm 8 \mathrm{mmHg}$. There was a statistically significant difference between the preoperative and one-year follow-up data $(p$ value $<0.001)$. However, there was no significant difference between the early postoperative and one-year followup. Conclusion: Septal myectomy for Hypertrophic Obstructive Cardiomyopathy (HOCM) is a safe procedure with good immediate and short-term results, and with good outcome if done by an experienced surgeon with good selection criteria.
\end{abstract}

Keywords: Septal myectomy; Hypertrophic obstructive cardiomyopathy (HOCM); Follow up after septal myectomy; Hypertrophic cardiomyopathies; Idiopathic hypertrophic subaortic stenosis (IHSS).

\section{INTRODUCTION}

Hypertrophic cardiomyopathy (HCM) was previously known as hypertrophic obstructive cardiomyopathy (HOCM) or idiopathic hypertrophic subaortic stenosis (IHSS). These two later nomenclatures are not accurate and thus not recently used as the septal and ventricular myocardium can hypertrophy without casing obstruction ${ }^{(1)}$. According to the European society of cardiology 2008, hypertrophic cardiomyopathies are defined as increased ventricular wall thickness or mass, in the absence of loading conditions such as hypertension or valve disease ${ }^{(2)}$.

In 2011, the ACC/AHA guidelines included also the pediatric practice, where the term HCM refers only to conditions with LV hypertrophy due to sarcomeric protein mutations without extracardiac or metabolic findings (3). In adults (based on echocardiographic findings) $\mathrm{HCM}$ is considered when the left ventricular wall thickness exceeds 15 $\mathrm{mm}$, with values of 13 to 14 considered borderline ${ }^{(4)}$.

The mitral valve is not uncommonly affected in HCM, whether structurally or functionally causing systolic anterior motion of the mitral valve (SAM) thus contributing to LV outflow tract obstruction ${ }^{(5)}$.

Cardiac conduction anomalies are common in HCM patients and sudden cardiac death is the most feared complication of HCM and is known to be mostly related to ventricular arrhythmias such as ventricular fibrillation (VF) and ventricular tachycardia (VT) ${ }^{(6)}$.

Gross morphological features in HCM include increased heart mass (weight), asymmetrical interventricular septal thickening and small left ventricular cavity. Sometimes, there is also associated right ventricular hypertrophy, dilated atria, and thickened elongated mitral valve leaflets ${ }^{(7,8)}$.

Hypertrophic cardiomyopathy can be subdivided into 2 types: Non-Obstructive: Characterized by abnormal diastolic function with normal, supranormal, or even impaired systolic function and obstructive: Which maybe Subaortic, midventricular and/or apical obstruction ${ }^{(9)}$.

Clinical significance of LVOT gradient: According to the LVOT transgradient HCM can be divided into three groups:

Basal (rest) obstruction: with a gradient equal to or more than $30 \mathrm{~mm} \mathrm{Hg}$ under resting conditions.

Labile (dynamic) obstruction: gradient is less than $30 \mathrm{mmHg}$ under resting conditions but exceeds 30 $\mathrm{mmHg}$ when physiologically provoked.

Non-obstructive: gradient is less than $30 \mathrm{mmHg}$ even when physiologically provoked. 
The most common presenting symptoms include dyspnea, which occurs in up to $90 \%$ of symptomatic patients, angina which occurs in $70 \%$ to $80 \%$ of patients, syncope and presyncope and palpitation (usually due to atrial fibrillation) ${ }^{(10)}$.

\section{There are 3 pathways of clinical progression:} sudden cardiac death due to ventricular tachyarrythmias, most commonly in patients under 35 years (including competitive athletes). Progressive heart failure with end stage systolic dysfunction. And Atrial fibrillation either paroxysmal or chronic with the risk of thromboembolism and stroke ${ }^{(11)}$.

Management of HCM: For symptomatic patients, medical treatment in the form of beta blockers, calcium channel blockers and other antiarrhythmic drugs can be useful to relief the symptoms especially dyspnea and angina, and to decrease the risk of sudden cardiac death due to arrhythmias ${ }^{(12)}$.

Surgical management: When maximal medical treatment fails to alleviate the symptoms of obstructive HCM, and with peak systolic gradient of $50 \mathrm{mmHg}$ at rest or with provocation, surgical myectomy has been the gold standard treatment for many decades ${ }^{(13)}$. Replacement of the mitral valve was once proposed to eliminate the dynamic LVOT obstruction. Other surgical options included modified Konno-Rastan aortoventriculoplast and apico-aortic conduit which are complex operations rarely needed for classic HCM patients ${ }^{(14)}$.

\section{PATIENTS AND METHODS}

This prospective study included a total of 31 patients who underwent septal myectomy at Kasr Al Ainy University Hospitals. Approval of the ethical committee and a written informed consent from all the subjects were obtained. This study was conducted between March 2014 and May 2018.

Exclusion criteria: Any patient with ischemic or rheumatic pathology or requiring any additional procedure.

All patients had the routine preoperative laboratory investigations. TTE was the main diagnostic tool. Cardiac MRI was done for a number of patients.

\section{Surgical Technique}

All patients were operated via standard full median sternotomy, with routine cannulation of the ascending aorta just proximal to the arch. Double staged venous cannulation was done except in 4 patients where additional mitral procedure was anticipated so bicaval cannulation was done. Venting of the LV was done via the right superior pulmonary vein. The septum was tackled via an oblique aortotomy. After retracting the aortic valve, septal myectomy was carried out starting 3 to $5 \mathrm{~mm}$ below the aortic annulus, in the area extending between the level of the right coronary ostium and the commissure between the right and left coronary cusps. The efficiency of myectomy was assessed after weaning from CPB by TEE, which was also useful to rule out iatrogenic ventricular septal defect.

\section{Statistical Analysis}

Data were statistically described in terms of mean \pm standard deviation $( \pm \mathrm{SD})$, median and range, or frequencies (number of cases) and percentages when appropriate. Comparison of numerical variables between the study groups in terms of different follow up periods was done using Student $t$ test for independent samples in comparing 2 groups when normally distributed and Mann Whitney $U$ test for independent samples when not normally distributed. Within group comparison of numerical variables was done using Wilcoxon signed rank test for paired (matched) samples. For comparing categorical data, McNemar test was used. Survival analysis was done using Kaplan Maier statistics calculating the mean and median survival time for each group with their 95\% CI and the corresponding survival graphs. $P$ values less than 0.05 was considered statistically significant and less than 0.001 considered highly significant. All statistical calculations were done using computer program SPSS (Statistical Package for the Social Science; SPSS Inc., Chicago, IL, USA) version 15 for Microsoft Windows.

Preoperative and postoperative clinical and echocardiographic data will be statistically compared regarding the following parameters:

1. Patient's symptomatology especially functional class of dyspnea (according to NYHA classification).

2. Peak gradient across the LVOT.

3. Septal wall thickness.

4. Degree of mitral regurgitation: for the sake of statistical analysis and according to advice of our statistician we converted the descriptive assessment of mitral incompetence to numerical grading as follows:

- No or trivial equals 0

- Mild incompetence 1

- Moderate incompetence 2

- Moderately severe 3

- Severe incompetence 4 N.B;

Because the number of patients is different at each follow up period, comparisons were made only of the data of those patients themselves who completed each specific period. For example, 10 patients completed 5 years follow up, so, statistical analysis 
will include only their own data not the whole group.

\section{RESULTS}

Demographic data: There were 17 males (54\%) and 14 females $(45 \%)$. The mean age in the male group was $31.6 \pm 14.3$ years, while for the female group it was $29.1 \pm 17.6$ years with no statistically significant difference between both sexes ( $p$ value >0.05)

Table (1): demographic data

\begin{tabular}{|l|l|l|}
\hline & MALE & FEMALE \\
\hline Number of patients & $17(54 \%)$ & $14(45 \%)$ \\
\hline Age (years) & $31.6 \pm 14.3$ years & $29.1 \pm 17.6$ years \\
\hline
\end{tabular}

Preoperative Echocardiographic data: data showed normal LV function in our patients. All patients had an LVOT peak gradient of more than 50 $\mathrm{mmHg}$. The peak gradient ranged from 53 to 172 $\mathrm{mmHg}$ with a mean of $102.4 \pm 24 \mathrm{mmHg}$. All of the patients had preoperative mitral regurge with a mean degree of $2.1 \pm 1.1$. the preoperative septal wall thickness ranged from 1.5 to $3.5 \mathrm{~cm}$ with a mean of $2.1 \pm 0.7 \mathrm{~cm}$.

Table (2): preoperative echocardiography

\begin{tabular}{|c|c|c|c|c|}
\hline & $\min$ & $\max$ & mean & SD \\
\hline $\begin{array}{c}\text { Pressure } \\
\text { gradient }\end{array}$ & $\begin{array}{c}53 \\
\mathrm{mmHg}\end{array}$ & $\begin{array}{c}172 \\
\mathrm{mmHg}\end{array}$ & 102.4 & \pm 24 \\
\hline Degree of MR & 1 & 4 & 2.1 & 1.1 \\
\hline SWT $(\mathrm{cm})$ & 1.5 & 3.5 & 2.1 & 0.7 \\
\hline
\end{tabular}

Operative data: The total bypass time ranged from 34 to $67 \mathrm{~min}$ with a mean of $44 \pm 6 \mathrm{~min}$. The crossclamp time ranged from 23 to 55 min with a mean of $31 \pm 5 \mathrm{~min}$. Intraoperative TEE showed a pressure gradient across the LVOT ranging from 4 to 20 mmHg with a mean of $7 \pm 6 \mathrm{mmHg}$, which was statistically significant in comparison to the preoperative values ( $\mathrm{p}$ value $<0.001$ ).

Table (3): Operative data

\begin{tabular}{|l|l|l|l|l|}
\hline & $\min$ & $\max$ & mean & SD \\
\hline CPB time & $34 \mathrm{~min}$ & $67 \mathrm{~min}$ & $44 \mathrm{~min}$ & \pm 6 \\
\hline $\begin{array}{l}\text { Cross clamp } \\
\text { time }\end{array}$ & $23 \mathrm{~min}$ & $55 \mathrm{~min}$ & $31 \mathrm{~min}$ & \pm 5 \\
\hline $\begin{array}{l}\text { Pressure } \\
\text { gradient }\end{array}$ & $4 \mathrm{mmHg}$ & $20 \mathrm{mmHg}$ & $7 \mathrm{mmHg}$ & \pm 6 \\
\hline
\end{tabular}

\section{Postoperative data:}

The mechanical ventilation time ranged from 3 to 19 hours with a mean of $7.4 \pm 3$ hours. 3 patients needed postoperative inotropic support (9.6\%). 2 patients had complete heart block $(6.4 \%)$ requiring temporary pacing. The total ICU stay ranged from 2 to 5 days with a mean of $2.2 \pm 0.7$ days. There was no in hospital mortality or within 30 days from discharge.

One year follow up: One patient died 7 months postoperatively due to non-cardiac related cause. Another patient needed permanent pace maker implantation 6 months after the operation due to complete heart block. Echocardiography done at one year follow up showed a peak systolic gradient across the LVOT ranging from 6 to $40 \mathrm{mmHg}$, with a mean of $18 \pm 8 \mathrm{mmHg}$. There was a statistically significant difference between the preoperative and one-year follow-up data ( $p$ value<0.001). However, there was no significant difference between the early postoperative and one-year follow-up ( $\mathrm{p}$ value $>0.05$ ).

Table (4): one-year follow-up

\begin{tabular}{|l|l|l|l|}
\hline & $\min$ & \multicolumn{1}{|c|}{ Max } & \multicolumn{1}{c|}{ Mean } \\
\hline preoperative & 53 & 172 & $102.4 \pm 24$ \\
\hline postoperative & 4 & 20 & $7 \pm 6$ \\
\hline One year & 6 & 40 & $18 \pm 8$ \\
\hline
\end{tabular}

\section{DISCUSSION}

our patients presented with higher PG more than most of other studies except for Swistel and Balaram (15), who reported a pre-PG of $135 \pm 43 \mathrm{mmHg}$. This study was done in USA and reported much higher gradient than most other studies with much larger numbers done also in USA, but they also reported a significant degree of SAM (dynamic obstruction) and MR in most of their patients. This might implicate that the higher gradients were due to the fact that most of their patient were in severe and advanced form of the disease, rather than a characteristic finding of their population. Apart from this study, our study reported higher gradients than other studies done in USA, Europe and Latin America. This might suggest that the Egyptian patients with HOCM shows a more severe form of obstruction. We and others had a mean cross clamp time to perform the septal myectomy of around 30 minutes $(16,17,18)$. In our study, the mean post-myectomy intra-operative $\mathrm{PG}$ was $7 \pm 6 \mathrm{mmHg}$, which shows highly significant statistical difference when compared to the mean pre-operative PG of $102.4 \pm 24 \mathrm{mmHg}$ (P value < 0.001). Maximum intraoperative gradient was $20 \mathrm{mmHg}$. McCully et al. ${ }^{(17)}$, and Swistel and Balaram (15) both also reported significant reduction of gradient postmyectomy, with similar mean intra-operative PG of $9 \pm 11$, and $10 \pm$ $18 \mathrm{mmHg}$ respectively. Ashikhmina et al. ${ }^{(18)}$ reported lower post-myectomy intra-operative PG with mean of $4 \pm 8 \mathrm{mmHg}$, but they also reported preoperative PG lower than most of the studies.

At one year follow up, the mean gradient across the LVOT dropped from $102.4 \pm 24 \mathrm{mmHg}$ to $18 \pm 8$ $\mathrm{mmHg}$, which was statistically significant. In another 
study done by Berg et al, the peak gradient in the left ventricular outflow tract decreased from $72+/-30$ $\mathrm{mmHg}$ (range, 31 to $144 \mathrm{~mm} \mathrm{Hg}$ ) to $6+/-4 \mathrm{mmHg}$ (19).

\section{CONCLUSION}

Septal myectomy for Hypertrophic Obstructive Cardiomyopathy (HOCM) is a safe procedure with good immediate and short-term results, and with good outcome if done by an experienced surgeon with good selection criteria.

\section{REFERENCES}

1. Maron M, Olivotto I, Zenovich A et al. (2006): Hypertrophic cardiomyopathy is predominantly a disease of left ventricular outflow tract obstruction. Circulation, 114 (21): 2232-9.

2. Elliott P, Andersson B, Arbustini E et al. (2008): Classification of the cardiomyopathies: a position statement from the European society of cardiology working group on myocardial and pericardial diseases. Eur. Heart J., 29: 270-6.

3. Gersh B, Maron B, Bonow $\mathrm{R}$ et al. (2011): a report of the American College of Cardiology Foundation/American Heart Association Task Force on Practice Guidelines. Circulation, 124: e783-831

4. Colan S (2010): Hypertrophic cardiomyopathy in childhood. Heart Fail. Clin., 6 (4): 433-44.

5. Levine RA, Vlahakes GJ, Lefebvre X, Guerrero JL, Cape EG, Yoganathan AP, Weyman AE (1995): Papillary muscle displacement causes systolic anterior motion of the mitral valve. Experimental validation and insights into the mechanism of subaortic obstruction. Circulation, 91 (4): 1189-95.

6. Barriales-Villa R, Centurión-Inda R, FernándezFernández $X$, Ortiz MF, Pérez-Alvarez $L$, Rodríguez García I, Hermida-Prieto M, Monserrat L (2010): Severe cardiac conduction disturbances and pacemaker implantation in patients with hypertrophic cardiomyopathy. Rev. española Cardiol., 63 (8): 9858.

7. Wang L, Seidman JG, Seidman CE (2010): Narrative review: harnessing molecular genetics for the diagnosis and management of hypertrophic cardiomyopathy. Ann. Intern. Med., 152 (8): 513-20.

8. Shirani J (2001): Abnormal Morphologic Features of Hypertrophic Cardiomyopathy. https://test.fac.org.ar/scvc/llave/cardio1/shirani/shiranii.htm

9. Said SM, Schaff HV, Abel MD, Dearani JA (2012): Transapical approach for apical myectomy and relief of midventricular obstruction in hypertrophic cardiomyopathy. J. Card. Surg., 27 (4): 443-8.

10. Maron BJ, Casey SA, Poliac LC, Gohman TE, Almquist AK, Aeppli DM (1999): Clinical course of hypertrophic cardiomyopathy in a regional United States cohort. JAMA., 281 (7): 650-5.

11. Maron BJ, Doerer JJ, Haas TS, Tierney DM, Mueller FO (2009): Sudden deaths in young competitive athletes: analysis of 1866 deaths in the United States, 1980-2006. Circulation, 119 (8): 1085 92.

12. Maron BJ, McKenna WJ, Danielson GK, Kappenberger LJ, Kuhn HJ, Seidman CE, Shah PM, Spencer WH 3rd, Spirito P, Ten Cate FJ, Wigle ED (2003): American College of Cardiology/ European Society of Cardiology clinical expert consensus document on hypertrophic cardiomyopathy. J. Am. Coll. Cardiol., 42 (9): 1687-713.

13. Dearani JA, Ommen SR, Gersh BJ, Schaff HV, Danielson GK (2007): Surgery Insight: septal myectomy for obstructive hypertrophic cardiomyopathy - the Mayo Clinic experience. Nat. Clin. Pract. Cardiovasc. Med., 4 (9): 503-512.

14. Metton O, Ali WB, Raisky O, Vouhé PR (2008): Modified Konno operation for diffuse subaortic stenosis. Multimed. Man.CardioThoracic Surg., 2008 (0915): 1-6.7

15. Swistel DG, Balaram SK (2006): Resection Plication, Release--the RPR procedure for obstructive hypertrophic cardiomyopathy. Anadolu Kardiyol. Derg., 6 (2): 31-6

16. Schönbeck MH, Brunner-La Rocca HP, Vogt PR, Lachat ML, Jenni R, Hess OM, Turina MI (1998): Long-term follow-up in hypertrophic obstructive cardiomyopathy after septal myectomy. Ann. Thorac. Surg., 65 (5): 1207-14.

17. McCully RB, Nishimura RA, Tajik AJ, Schaff HV, Danielson GK (1996): Extent of clinical improvement after surgical treatment of hypertrophic obstructive cardiomyopathy. Circulation, 94 (3): 467-71.

18. Ashikhmina EA, Schaff HV, Ommen SR, Dearani JA, Nishimura RA, Abel MD (2011): Intraoperative direct measurement of left ventricular outflow tract gradients to guide surgical myectomy for hypertrophic cardiomyopathy. J. Thorac. Cardiovasc. Surg., 142 (1): 53-9.

Berg JM, Suttorp MJ, Knaepen PJ, Ernst SM, Vermeulen FE, Jaarsma W (1994): Hypertrophic obstructive cardiomyopathy Initial results and longterm follow-up after Morrow septal myectomy. Circulation, 90(4):1781-5. 